\title{
CONSERVAÇÃO DO VIGOR DE SEMENTES DE PINHA Anonna squamosa L. ${ }^{1}$
}

Otoniel Magalhães Morais² ${ }^{2}$ Rosa Honorato de Oliveira ${ }^{3}$, Sirleine Lima de Oliveira ${ }^{4}$, Verônica Barbosa Santos ${ }^{4}$ e José Carlson Gusmão da Silva ${ }^{5}$

\begin{abstract}
RESUMO - Estudos sobre as condições ideais de armazenamento para cada espécie são muito importantes porque sementes armazenadas em condições inadequadas perdem o vigor ao longo do tempo de armazenamento. O objetivo deste trabalho foi avaliar o vigor de sementes de pinha acondicionadas, por cinco períodos ( 0 , 3, 6, 9 e 12 meses), em dois ambientes (ambiente natural e em geladeira) e em duas embalagens (saco de papel e saco plástico). O experimento foi realizado em fatorial 5 × 2 × 2, em delineamento inteiramente casualizado com quatro repetições de 50 sementes. Foi avaliado o teor de água das sementes e realizados testes de vigor (porcentagem de emergência, índice de velocidade de emergência de plântulas e massa seca de plântulas). Concluiuse que o teor de água que mantém o vigor das sementes de pinha durante o armazenamento é de 8,49\%. As sementes acondicionadas em embalagem plástica perderam rapidamente o vigor, enquanto sementes de pinha armazenadas em embalagem de papel em condições ambientais permaneceram viáveis por seis meses.
\end{abstract}

Palavras-chave: Annona squamosa L.; Sementes; Acondicionamento.

\section{CONSERVATION OF SEED VIGOR OF SUGAR APPLE Annona squamosa L.}

\begin{abstract}
Studies of suitable conditions on seed storage for each species are very important, because seeds stored under no-suitable conditions, lose their vigor. Thus, the present study aimed to evaluate the seeds vigor of sugar apple in five storage periods (0, 3, 6, 9 and 12 months), two storage conditions (noncontrolled environment and refrigerator) and two packaged (paper and plastic bags). The experiment was carried out in a factorial $5 \times 2 \times 4$, in an entirely randomized design with 4 replications of 50 seeds. The moisture content was evaluated and vigor tests (percentage emergence, emergence speed index and seedlings dry matter) were performed. We concluded that the moisture content at $8.49 \%$ maintained the vigor of sugar apple seeds during the storage. Furthermore, we observed that seeds stored in plastic bags lost their vigor, while those stored in paper remained viable in non-controlled environment for six months.
\end{abstract}

Keywords: Annona squamosa L.; Seeds; Storage.

\section{INTRODUÇÃO}

A pinha (Annona squamosa L.) é uma fruta pertencente à família Annonaceae que tem sua produção e consumo em expansão no Brasil nos últimos anos (PELINSON, 2003), como frutíferas comerciais (MENEGAZZO et al., 2012). Entre as anonáceas, é considerada a de maior expressão, sendo geralmente consumida in natura (GOUVEIA et al., 2006). Estima-se que o Brasil possui área plantada de pinha em torno de 10.000 ha (BRAGA SOBRINHO et al., 2010). Apesar da sua origem exótica na América Tropical, provavelmente Ilhas Trinidad, a planta apresenta boa adaptação a diversas condições de clima no país, podendo ser

\footnotetext{
${ }^{1}$ Recebido em 27.10.2008 aceito para publicação em 07.11.2013.

${ }^{2}$ Departamento de Fitotecnia e Zootecnia da Universidade Estadual do Sudoeste da Bahia, Escola de Agronomia, Bahia, Brasil. E-mail:<otoniel@uesb.br>.

${ }^{3}$ Unidade Acadêmica de Serra Talhada da Universidade Federal Rural de Pernambuco, UFPE. E-mail:<honoratorh@gmail.com>

${ }^{4}$ Laboratório de Sementes, Universidade Estadual do Sudoeste da Bahia, Vitória da Conquista, BA, Brasil. E-mail: <sirleinelimadeoliveira@yahoo.com>e <E-mail:verabarbosa@hotmail.com>.

${ }^{5}$ Centro Federal de Educação Tecnológica, CEFET. <E-mail: carlsongusmao@hotmail.com>.
} 
encontrados em pomares comerciais nas Regiões Nordeste e Sudeste (PELINSON, 2003). Nos Estados da Bahia, de Pernambuco, de Alagoas, de Minas Gerais e de São Paulo, encontram-se plantios irrigados com bom nível tecnológico. Na Região Nordeste, a Bahia é o principal produtor, seguido de Pernambuco e Alagoas (BRAGA SOBRINHO, 2010).

As anonáceas cultivadas comercialmente têm sido propagadas através de enxertia, sendo o porta-enxerto obtido por sementes (STENZEL et al., 2003), apesar da heterogeneidade das mudas formadas e da baixa porcentagem de germinação (MENEGAZZO et al., 2012), em razão da presença de dormência em suas sementes (KAWATI, 1992). Apesar de a presença de dormência em sementes de pinha já ser um fenômeno comprovado, ainda são desconhecidos os mecanismos que levam à dormência. De acordo com Menegazzo et al. (2012) e Stenzel et al. (2003), as sementes dessa espécie apresentam substâncias inibidoras de germinação que, conjuntamente com um tegumento resistente e impermeável, dificultam a germinação. Porém, estudos desenvolvidos por Ferreira et al. (1997) sobre a pinha descartaram o impedimento físico como causa da dormência nas sementes da espécie.

Estudos desenvolvidos por Sousa et al. (2008) mostraram que, apesar de a pinheira apresentar sementes com tegumento rígido, sua dormência não se deve à impermeabilidade do tegumento à água. Ferreira et al. (1997) confirmaram essa teoria quando realizaram a curva de embebição de sementes de pinha e não verificaram impedimento físico à entrada de água. Para Dornelles et al. (2002), a dormência das sementes de pinha pode ser atribuída à imaturidade do embrião e, dessa forma, como no momento da maturidade dos frutos o embrião ainda não está completamente desenvolvido, sementes requerem tratamento pósmaturação para que germinem. Dentro dessa perspectiva, é de se esperar que o armazenamento das sementes de pinha possa contribuir para que a espécie expresse todo o seu potencial germinativo. Lobo et al. (2007) atestaram que o bloqueio da germinação de anonáceas é do tipo morfofisiológico e, assim, pode ser superado pelo armazenamento. Pinto e Geru (1984) também compartilharam dessa opinião.

Apesar de a dormência das sementes de pinha ser um fenômeno comprovado, ainda assim existem controvérsias sobre os fatores envolvidos no mecanismo de dormência, e, conforme preconizaram Nietsche et al. (2005), os estudos sobre métodos eficientes da superação de dormência das sementes dessa espécie ainda são incipientes. Nesse contexto, Mendonça et al. (2007) recomendaram estudos que possam esclarecer o tipo de mecanismo envolvido na dormência das sementes de anonáceas, incluindo a pinha, na busca da forma mais adequada de superação da sua dormência, sem que haja comprometimento do vigor das mudas.

Para a efetiva conservação de sementes, é necessário o conhecimento prévio do seu comportamento fisiológico durante o armazenamento, já que nem todas as sementes são tolerantes à dessecação, exigindo condições especiais de armazenamento (HONG et al., 1996).

A conservação do vigor das sementes, de modo geral, é de grande importância, e o armazenamento, uma vez aplicado de modo adequado, vai diminuir a velocidade de deterioração, que se caracteriza por ser um processo irreversível (DELOUCHE et al., 1973). No entanto, as condições de armazenamento irão interferir no período máximo desse armazenamento e na germinação final das sementes, podendo até levar a semente a algum tipo de dormência secundária (SCALON et al., 2006). Dessa forma, o armazenamento em condições inadequadas irá contribuir para a redução da qualidade fisiológica das sementes (ALMEIDA; MORAIS, 1997).

Entre os fatores mais importantes no armazenamento, destacam-se o tipo de embalagem e o ambiente de conservação, que influenciam diretamente na conservação das sementes de algumas espécies frutíferas (ANDRADE; FERREIRA, 2000).

De acordo com Pedrosa et al. (1999), as condições ideais de conservação de sementes são aquelas em que as atividades metabólicas são reduzidas ao mínimo, pelo abaixamento da umidade relativa e temperatura no ambiente de armazenamento, sendo elas específicas.

A umidade ideal na conservação das sementes deve estar relacionada ao tipo de embalagem. Sementes conservadas em embalagens que permitem trocas de vapor da água com o ar atmosférico, ou seja, permeáveis, podem absorver água sob a alta umidade relativa do ar, deteriorando-se com facilidade (CROCHEMORE, 1993). Especialmente em condições ambientais, podem perder mais rapidamente o vigor durante o período de armazenamento (SOUZA et al., 2005), pelo fato de apresentarem oscilações em função dos ganhos e perdas da umidade relativa do ar e da temperatura nesse ambiente (TORRES, 2005). Em contrapartida, em armazenamento 
refrigerado as sementes podem sofrer redução nas reações metabólicas do embrião, conservando melhor o vigor (SCALON et al., 2006).

O armazenamento das sementes em embalagens impermeáveis possibilita a conservação mais prolongada, porque assegura a manutenção do teor de umidade adequado, levando ao menor risco de perda da qualidade fisiológica por deterioração (CORLETT et al., 2007). Justice e Bass (1978) destacaram que nesse tipo de embalagem o teor de umidade das sementes da maioria das espécies ortodoxas deve estar entre 3 e $7 \%$.

As respostas às condições de armazenamento das sementes variam em função da espécie, tendo sido relatados na literatura manutenção na qualidade fisiológica de sementes de diversas espécies pela utilização de embalagem de papel e plástica em condições de refrigeração ou natural. Nas espécies florestais, o estudo das condições de armazenamento tem sido feito exaustivamente, porém para as frutíferas, especialmente as do gênero Annona, as informações sobre o efeito do armazenamento de sementes sobre a manutenção da sua viabilidade são escassas. Isso porque Dornelles et al. (2002), estudando condições de armazenamento de sementes de anonáceas, verificaram que as sementes de pinha em dessecador mantiveram a qualidade fisiológica, em comparação com aquelas mantidas em condições naturais e em geladeira. As sementes de graviola não foram afetadas pelas condições de armazenamento utilizadas durante todo o período. Com relação ao tempo de armazenamento, observaram que as sementes de pinha podem ser armazenadas por seis meses e as de graviola, por nove meses, sem perda da viabilidade.

Tomando como base um estudo sobre armazenamento de sementes de araticum por 12 meses em condições ambientes e em sacos de papel, Bernardes et al. (2007) verificaram que o armazenamento comprometeu o vigor, não recomendando, então, seu armazenamento em condição ambiente. O estudo atribuiu esse resultado, provavelmente, à forma de armazenamento, tendo em vista ser esse fator determinante no processo germinativo de sementes dessa espécie.

Em sementes de maracujá-doce, Alves et al. (2006) observaram que o armazenamento sob refrigeração mostrou-se superior àquele em temperatura ambiente, indicando que a baixa temperatura associada à umidade relativa conservou o vigor das sementes armazenadas.
Comparando condições de armazenamento de sementes de maracujá-doce por 12 meses em ambiente não controlado (em sacos de papel), câmara seca (em saco de papel) e câmara fria (em saco de polietileno), Osipi e Nakagawa (2005) não verificaram influência dos ambientes nos seis meses iniciais, porém, aos 12 meses, observaram que sementes com grau de umidade próximo a $10 \%$ e em embaladas em sacos de polietileno garantiram a conservação do seu vigor. O armazenamento em ambiente não controlado e em saco de papel afetou negativamente o desempenho das mudas de maracujá-doce.

Brasileiro et al. (2011), estudando o armazenamento de sementes de nêsperas em embalagens de papel e de plástico na geladeira, verificaram que a embalagem plástica conservou a umidade das sementes, que se mantiveram viáveis por 180 dias. O armazenamento em sacos de papel decresceu a viabilidade das sementes bruscamente aos 30 dias, a qual foi reduzida a zero aos 60 dias, quando a umidade atingiu $25 \%$, revelando comportamento recalcitrante da espécie. Figueirêdo (2012), avaliando a resposta de sementes de graviola à dessecação, observaram a manutenção da viabilidade de sementes com teor de água em torno de 7\%, revelando o caráter ortodoxo da espécie.

Tomando como base a importância econômica dessa espécie, este trabalho teve como objetivo avaliar as condições de armazenamento de sementes de pinha na manutenção do seu vigor.

\section{MATERIAL E MÉTODOS}

O experimento foi conduzido no Laboratório de Sementes da Universidade Estadual do Sudoeste da Bahia - Vitória da Conquista, BA. Utilizaram-se sementes de pinha (Annona squamosa L.) provenientes de frutos maduros coletados de um pomar comercial de aproximadamente 1,0 ha, no Município de Anagé, BA.

Os frutos foram despolpados e suas sementes, lavadas em água corrente e secas com papel-toalha para retirar o excesso de água. Em seguida, foram colocadas para secar à sombra por 20 dias, no ambiente de laboratório, e tratadas com fungicida Captan ${ }^{\circledR}$ $\left(2 \mathrm{~g} \mathrm{~kg}^{-1}\right)$. As sementes não sofreram nenhum tratamento pré-germinativo para superação da dormência.

Para instalação do experimento, as sementes foram divididas em quatro lotes, acondicionadas em dois tipos de embalagens (saco de papel e saco plástico 
transparente) e armazenadas em dois ambientes (ambiente natural do laboratório e de geladeira $\left(\mathrm{t}=6-8^{\circ} \mathrm{C}\right)$ ) por 12 meses. A umidade relativa média do ar no laboratório variou de 60 a $90 \%$ ao longo do período do experimento. Já a temperatura média variou de 21 a $26^{\circ} \mathrm{C}$ no período de maio a dezembro de 2003. A partir desse período, registrou-se queda na temperatura do ar, atingindo em torno de $18{ }^{\circ} \mathrm{C}$ ao final do período de armazenamento.

O experimento foi instalado no esquema fatorial $5 \times 2 \times 2$, em delineamento inteiramente casualizado, em com quatro repetições de 50 sementes por tratamento. A semeadura foi realizada em bancadas no laboratório, utilizando-se 50 sementes distribuídas em bandejas plásticas (45 cm x $30 \mathrm{~cm}$ x $7 \mathrm{~cm}$ ) com areia lavada e esterilizada.

Antes do armazenamento (tempo zero) e nos períodos preestabelecidos, procedeu-se às avaliações do teor de água das sementes e aos testes de vigor (porcentagem de emergência, índice de velocidade de emergência de plântulas e massa seca de plântulas).

O teor de água das sementes foi determinado pelo método da estufa a $105^{\circ} \mathrm{C}$ durante $24 \mathrm{~h}$ (BRASIL, 2009), em quatro repetições de 50 sementes em cada teste. Após esse tempo, as amostras foram retiradas da estufa, esfriadas em dessecador contendo sílica-gel e pesadas novamente em uma balança de precisão com três casas decimais. A porcentagem de emergência de plântulas foi efetuada, computando-se diariamente o número de plântulas normais emergidas do $5^{\circ}$ ao $15^{\circ}$ dia após a semeadura. $\mathrm{O}$ índice de velocidade de emergência foi determinado pela fórmula IVE = ÓNi/Di, em que Ni é o número de sementes emergidas em Di, dias após a semeadura. A massa seca de plântulas foi determinada ao final do teste de emergência pelo método da estufa a $105^{\circ}$ por $24 \mathrm{~h}$ e, em seguida, elas foram pesadas em balança de precisão com três casas decimais (BRASIL, 2009).

Os dados foram submetidos à regressão polinomial, utilizando-se o programa SISVAR 4.6 (FERREIRA, 1999). Para escolha do modelo de regressão que melhor se ajustasse aos dados observados, levou-se em consideração o fato de o modelo de maior ordem apresentar grau significativo e valor do coeficiente de determinação $\left(\mathrm{R}^{2}\right)$; do contrário, optou-se por apresentar apenas a média dos pontos observados.

Revista Árvore, Viçosa-MG, v.38, n.1, p.125-132, 2014

Revista Árvore, Viçosa-MG, v.38, n.1, p.125-132, 2014

\section{RESULTADOS E DISCUSSÃO}

O teor de água inicial das sementes após o beneficiamento $(16,8 \%)$ foi mantido durante todo o período de armazenamento, quando as sementes foram conservadas em embalagem plástica, independentemente do local de armazenamento (Figura 1). Esse teor, segundo Justice e Bass (1978), encontrava-se acima do adequado para armazenamento da maioria das espécies ortodoxas (3 e 7\%). Lopes et al. (2002) também observaram manutenção da umidade durante todo o período de armazenamento em sementes de ingá acondicionadas em embalagem impermeável. Quando as sementes foram armazenadas em embalagem de papel e em geladeira, a umidade foi reduzida até os três meses após o início do armazenamento, quando atingiu aproximadamente $5 \%$, porém se manteve constante pelo resto do período de armazenamento.

Os teores de água obtidos no armazenamento em geladeira estão dentro dos padrões normais para sementes ortodoxas. Contudo, os dados de porcentagem de emergência (Figura 2) revelaram que sementes com $5 \%$ de umidade apresentaram taxa de emergência inferior a 60\%, comprometendo, dessa forma, o vigor das plântulas.

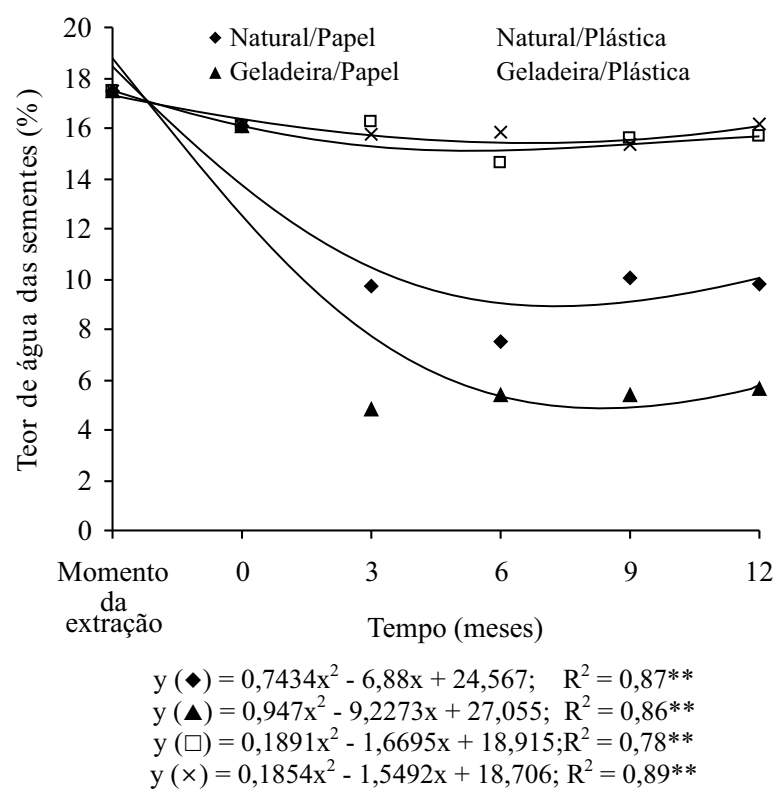

Figura 1 - Teor de água (\%) das sementes de pinha submetidas a ambientes e embalagens durante o armazenamento.

Figure 1 - Moisture content (\%) of sugar apple seeds as a function of environments, packages and storage periods. 


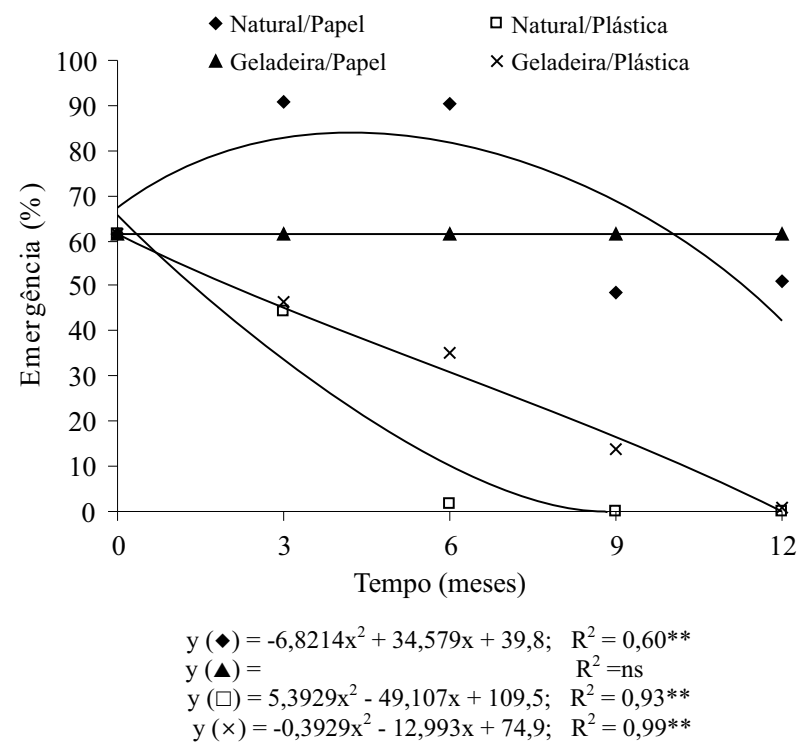

Figura 2 - Emergência (\%) de plântulas de pinha submetidas a ambientes e embalagens durante o armazenamento.

Figure 2 - Seedlings emergence (\%) of sugar apple seeds as a function of environments and packages and storage periods.

A embalagem de papel, dada à sua capacidade de troca gasosa com o ambiente, contribuiu para que o teor de umidade das sementes fosse reduzido, ao longo do tempo, para os dois ambientes (Figura 1). Apesar disso, em condições naturais os teores médios de umidade das sementes apresentaram-se mais altos $(10,62 \%)$ em relação ao armazenamento em geladeira (7,45\%), 12 meses após o início do armazenamento, com os valores oscilando ao longo do tempo de armazenamento. Isso certamente está relacionado às condições de temperatura e umidade relativa do ar do ambiente de laboratório por ocasião do armazenamento das sementes. As embalagens impermeáveis, que não permitem essa troca, conservam a umidade inicial das sementes durante todo o período de armazenamento, favorecendo sua deterioração caso o teor inicial de água nas sementes esteja acima do tolerado para armazenamento naquelas condições. Por isso, os tipos de embalagem utilizados no acondicionamento das sementes durante $\mathrm{o}$ armazenamento assumem significativa importância na preservação de sua viabilidade e vigor (CARVALHO; NAKAGAWA, 2000).

Com isso, pode-se inferir que o armazenamento de sementes de pinha só deverá ser realizado em embalagem plástica, quando o seu teor de umidade estiver próximo daquele que garanta a máxima germinabilidade que, para essa espécie, se mostrou ser em torno de $8,5 \%$. No entanto, caso as sementes apresentem teor de umidade além desse, devem ser armazenadas em embalagem de papel, pois esse tipo de embalagem favorece a perda de água ao longo do armazenamento. Nessa condição, é importante atentar para o período máximo de armazenamento capaz de manter a viabilidade das sementes.

A porcentagem de emergência das plântulas de pinha (Figura 2) durante o armazenamento variou com o ambiente e com o tipo de embalagem de armazenamento. A resposta do ambiente esteve condicionada à embalagem utilizada, quando esta pareceu ser mais importante que o ambiente. Quando o acondicionamento foi realizado em embalagem de papel em ambiente natural, detectou-se incremento na porcentagem de plântulas emergidas até seis meses de armazenamento (90\%). Quando o armazenamento se prolongou além desse tempo, a taxa de emergência foi reduzida a $50 \%$, aos nove meses, quando houve estabilização dos valores.

Estudos sobre efeito das condições de armazenamento no potencial germinativo de sementes têm sido realizados, obtendo-se, na maioria das vezes, resultados bastante expressivos. Alves e Lin (2003) também verificaram rápida redução no vigor de sementes de feijão após seis meses de armazenamento. Dornelles et al. (2002), estudando condições de armazenamento de sementes de A. squamosa L. e A. muricata L., concluíram que elas podem ser armazenadas durante seis e 12 meses, respectivamente, sem perder a viabilidade, portanto corroborando os resultados deste trabalho.

Quando as sementes foram armazenadas em sacos de papel sob refrigeração (geladeira), a taxa de emergência, que inicialmente estava em torno de $60 \%$, manteve-se constante ao longo do tempo de armazenamento (Figura 2). Entretanto, o armazenamento em embalagem plástica, independentemente do ambiente (natural ou geladeira), comprometeu completamente a porcentagem de emergência das plântulas, promovendo decréscimos significativos e constantes ao longo do período do armazenamento. Embora essa queda tenha ocorrido independentemente do ambiente, ela foi mais severa quando as sementes foram armazenadas em condições naturais. As sementes submetidas a essa condição não permitiram a emergência das plântulas a partir dos seis meses de armazenamento. A manutenção dos altos 
teores de umidade inicial nas sementes de pinha (Figura 1) pode ter favorecido a deterioração destas, comprometendo, dessa forma, a capacidade germinativa das sementes armazenadas em embalagem plástica (Figura 2). Lopes et al. (2002) também observaram que sementes acondicionadas em embalagem impermeável mantiveram sua umidade durante todo o período de armazenamento, independentemente do ambiente de armazenamento, a exemplo do que ocorreu neste experimento.

Desses resultados, depreende-se que a embalagem foi mais importante para vigor (\% de emergência) do que o ambiente de armazenamento, pois a embalagem de papel para o acondicionamento das sementes em condições naturais de laboratório promoveu incrementos na porcentagem de emergência a valores próximos de 90\% (Figura 2). Essa resposta revela a eficiência desse tipo de embalagem para armazenamento de sementes de pinha em condições naturais, contudo, se o armazenamento for realizado sob condições de refrigeração, a embalagem plástica torna-se imprópria para esse fim. Dessa forma, a embalagem plástica não representa boa alternativa para o armazenamento de sementes de pinha, por reduzir drasticamente a sua capacidade germinativa, independentemente do local de armazenamento.

O vigor representado pelo Índice de Velocidade de Emergência das plântulas (IVG) (Figura 3) não sofreu influência do ambiente de armazenamento, mas variou ao longo do período em função do tipo de embalagem utilizado. Quando as sementes foram acondicionadas em embalagem de papel, observaram-se incrementos no IVG até seis meses $(1,88)$, detectando-se redução nos valores a partir daí até o final do armazenamento, quando o IVG atingiu valores próximos daqueles constatados no início do armazenamento $(0,67)$. Entretanto, quando no acondicionamento das sementes foi utilizada a embalagem plástica, o IVG inicial $(0,67)$ foi mantido até os três meses; acumulou queda ao longo do período, com perda total da viabilidade aos 12 meses. $\mathrm{O}$ alto vigor (IVE) das plântulas mantido pelo armazenamento das sementes (Figura 3) até seis meses, em embalagem permeável, está ligado ao equilíbrio higroscópico atingido pelas sementes naquelas condições (TORRES, 2005). As embalagens impermeáveis, como não permitem essa troca, conservaram a umidade inicial das sementes durante todo o período de armazenamento, favorecendo sua deterioração, cujo

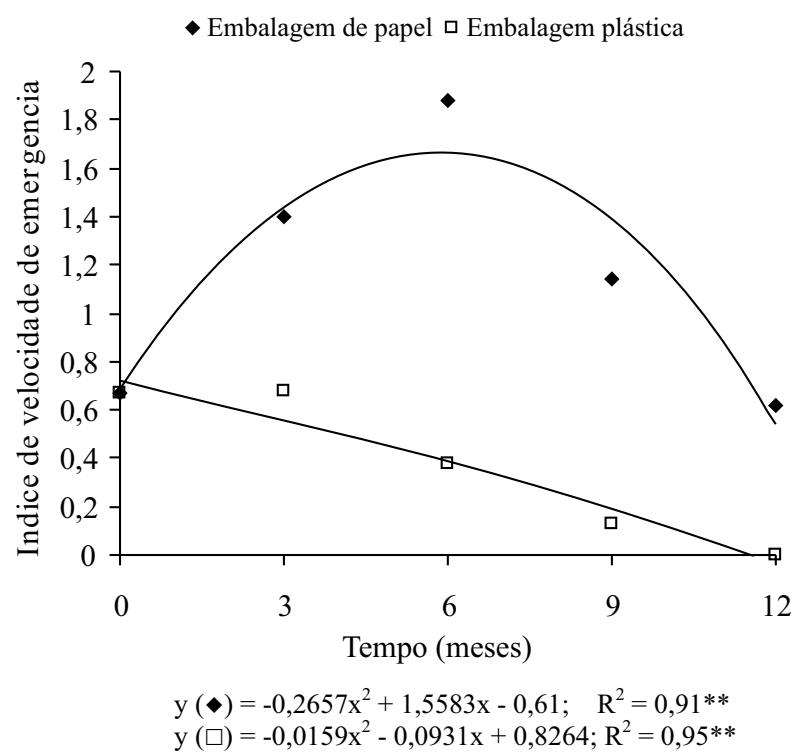

Figura 3-Índice de velocidade de emergência (IVG) de plântulas de pinha submetidas a tipos de embalagens durante o armazenamento.

Figure 3-Speed emergence index (IVE) of sugar apple seedlings as a function of packages and storage periods.

efeito foi proporcional ao tempo de armazenamento. Assim, o armazenamento das sementes de pinha em embalagem de papel contribuiu para incrementar o vigor (IVG) até os seis meses. Na embalagem plástica, o vigor inicial das sementes foi mantido somente até os três meses de armazenamento.

A massa seca de plântulas de pinha (Figura 4) foi seriamente afetada pelo tempo de armazenamento, não sofrendo influência do ambiente nem do tipo de embalagem. Até os seis meses, observou-se acúmulo significativo de massa seca, porém esta foi reduzida acentuadamente ao final do período de armazenamento (nove meses). Esses resultados concordam com os obtidos por Nakagawa (1994), segundo os quais, durante a germinação, as sementes vigorosas proporcionam maior transferência de massa seca de seus tecidos de reserva para o eixo embrionário, originando plântulas com maior peso, em razão do maior acúmulo de matéria.

Assim, na preservação do vigor de plântulas de pinha, o tempo de armazenamento das sementes não deve ultrapassar os seis meses, porque a partir desse período se inicia a perda de massa seca, comprometendo o desenvolvimento posterior das plântulas. 


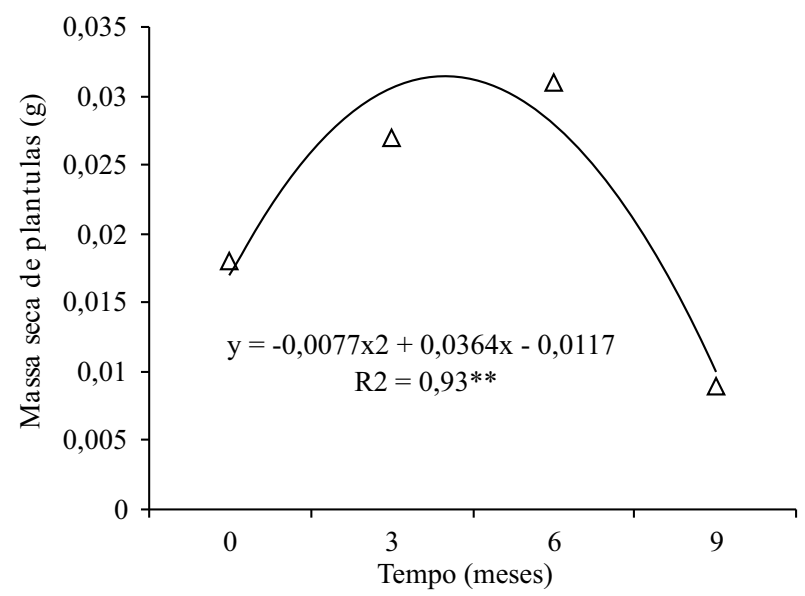

Figura 4 - Acúmulo de massa seca de plântulas de pinha em função do período de armazenamento das sementes.

Figure 4-Dry matter accumulation (g) of sugar apple seedlings as a function of storage periods.

\section{CONCLUSÕES}

O maior vigor é obtido com o armazenamento das sementes em embalagem de papel em condições naturais.

O tempo máximo de armazenamento é de seis meses. Depois disso, há comprometimento do vigor das sementes.

A embalagem plástica mostra-se ineficiente para armazenar as sementes de pinha com altos teores de umidade, especialmente em condições ambientais.

O teor de umidade das sementes capaz de preservar o vigor ficou estabelecido em 8,49\%.

\section{REFERÊNCIAS}

ALMEIDA, F. A. C.; MORAIS, J. S. Efeito do beneficiamento, tipo de embalagem e ambiente de armazenamento na qualidade fisiológica de sementes de amendoim. Revista Brasileira de Armazenamento, v.22, n.2, p.27-33, 1997.

ALVES, A. C.; LIN, H. S. Tipos de embalagem, umidade inicial e período de armazenamento em sementes de feijão. Scientia Agricola, v.4, n.1-2, p.21-26, 2003.

ALVES, Z.C. et al. Efeito da temperatura de armazenamento e de fitoreguladores na germinação de sementes de maracujá doce e desenvolvimento inicial de mudas. Acta Scientiarum: Agronomy, v.28, n.3, p.441-448, 2006.
ANDRADE, R. N. B.; FERREIRA, A. G. Germinação e armazenamento de sementes de uvaia (Eugenia pyriformis Camb.) - Myrtaceae. Revista Brasileira de Sementes, v.22, n.1, p.118-125, 2000.

BERNARDES, T. G. et al. Efeito do armazenamento e de fitohormônios na qualidade fisiológica de sementes de araticum (Annona crassiflora Mart.). Pesquisa Agropecuária Tropical, v.37, n.3, p.163-168, 2007.

BRAGA SOBRINHO, R. Potencial de exploração de anonáceas no Nordeste do Brasil. In: SEMANA INTERNACIONAL DA FRUTICULTURA, FLORICULTURA E AGROINDÚSTRIA, 17., 2010, Fortaleza. Anais...,Fortaleza: Embrapa Agroindústria Tropical, 2010. Disponível em:<www.ceinfo.cnpat.embrapa/arquivos/ artigo_3425.pdf.> Acesso em: 23 dez. 2012.

BRASIL. Ministério da Agricultura, Pecuária e Abastecimento. Regras para análise de sementes. Brasília: 2009. 395p.

BRASILEIRO, B. G.et al. Qualidade fisiológica de sementes de nêspera armazenadas em diferentes embalagens. Revista Brasileira

Fruticultura, v. especial, p.686-691, 2011.

CARVAlHO, N. M.; NAKAGAVA, J. Sementes: ciência, tecnologia e produção. Jaboticabal: FUNEP, 2000. 588p.

CORLETT, F. M. F.et al. Qualidade fisiológica de sementes de urucum armazenadas em diferentes ambientes e embalagens. Revista Brasileira de Sementes, v.29, n.2, p.148-158, 2007.

CROCHEMORE, M. L. Conservação de sementes de tremoço (Lupinus angustifolius L.) em diferentes embalagens. Revista Brasileira de Sementes, v.15, n.2, p.227-231, 1993.

DELOUCHE, J. C.; BASKIN, C. C. Accelerated aging techniques for predicting the relative storability of seed lots. Seed Science and Technology, v.1, n.2, p.427-452, 1973.

DORNELLES, A. L. C.; LIMA, A. R.; CAMPOS, V. C. Avaliação do potencial de armazenamento de sementes de Annona crassiflora MART, Annona muricata L.e Annona squamosa L. In: CONGRESSO BRASILEIRO DE FRUTICULTURA, 17., 2002, Belém. Anais...Fortaleza: SBF, 2002. CD ROM.

Revista Árvore, Viçosa-MG, v.38, n.1, p.125-132, 2014 
FERREIRA, D. F. SISVAR.Versão 4.6. 1999. Disponível em <http://www.dez.ufla.br/danieltf/ SISVAR.

FERREIRA, G. et al. Imbibition study of sugar apple (Annona squamosa L.) and atemoya (Annona squamosa L. x A. Cherimola Mill.) seeds. In: CONGRESSO INTERNACIONAL DE ANONACEAS, 1., 1997, Chapingo. Memorias... Chapingo: Universidad Autónoma Chapingo, 1997.

Figueirêdo, G. R. G. Propagação de gravioleira: vigor de sementes sob dessecação, estaquia e miniestaquia. 2012. 67f. Dissertação (Mestrado em Produção Vegetal) Universidade de Santa Cruz, Ilhéus, 2012.

GOUVEIA, D. S. et al. Avaliação físicoquímica e teste de aceitação sensorial do suco de pinha e do blend pinha-leite. Revista Brasileira de Produtos Agroindustriais, v.8, n.2, p.127-133, 2006.

HONG, T. D.; LININGTON, S.; ELLIS, R. H. Seed storage behaviour: a compendium. Rome: International Plant Genetic Resources Institute, 1996. (Handbooks for Genebanks, 4).

JUSTICE, O. L.; BASS, L. N. Principles and practices of seed storage. Washington: USDA, 1978. 289p. (Agriculture Handbook, 506).

KAWATI, R. O cultivo da atemoia. In: DONADIO, L. C.; MARTINS, A. B. G.; VALENTE, J. P. (Ed.). Fruticultura tropical. Jaboticabal: FUNEP, 1992. p.39-70.

LOBO, M. et al. Categorización de la germinación y la latencia en semillas de chirimoya (Annona cherimola L.) y guanábana (Annona muricata L.), como apoyo a programas de conservación de germoplasma. Agronomía Colombiana, v.25, n.2, p.231-244, 2007.

LOPES, K. P. et al. Comportamento de sementes de Inga sp. durante o armazenamento. In: CONGRESSO BRASILEIRO DE FRUTICULTURA, 17., 2002, Belém. Anais...Fortaleza: SBF, 2002. CD ROM.

MENDONÇA, V. et al. Superação de dormência e profundidade de semeadura de sementes de gravioleira. Revista Caatinga, v.20, n.2, p.73-78, 2007.
NAKAGAWA, J. Testes de vigor baseados na avaliação das plântulas. In: VIEIRA, R.D.; CARVALHO, N.M. Teste de vigor em sementes. Jaboticabal: FUNEP, 1994. p.49-85.

NIETSCHE, S. et al. Tratamentos físicos e químicos na emergência e no crescimento de plântulas de pinheira. Bragantia, 64, n.3, p.411416, 2005.

OSIPI, E. A. F.; NAKAGAWA, J. Avaliação da potencialidade fisiológica de sementes de maracujádoce (Passiflora alata Dryander) submetidas ao armazenamento. Revista Brasileira Fruticultura, v.27, n.1, p.52-54, 2005.

PEDROSA, J. P. et al. Teores de bixina e proteína em sementes de urucum em função do tipo e do período de armazenagem. Revista Brasileira de Engenharia Agrícola e Ambiental, v.3, n.1, p.121-123, 1999.

PELINSON, G. J. B. Efeito de técnicas visando melhoria da qualidade e produção de pinha (Annona squamosa L.) no período de entressafra. 2003. $118 f$. Dissertação (Mestrado em Agronomia) Universidade Estadual Paulista- Faculdade de Engenharia, Ilha Solteira, 2003.

PINTO, A. Q.; GENU, P. J. C. Contribuição do estado técnico-científico da graviola (Annona muricata L.). In: CONGRESSO BRASILEIRO DE FRUTICULTURA, 7., 1984, Florianópolis. Brasil. Anais... Florianópolis: SBF, 1984.

SCALON, S. P. Q. et al. Armazenamento e tratamentos pré-germinativos em sementes de jacarandá (Jacaranda cuspidifolia Mart.). Revista Árvore, v.30, n.2, p.179-185, 2006.

SOUSA, S. A. et al. Superação da dormência em sementes de pinha. Caatinga, v.21, n.4, p.118-121, 2008.

STENZEL, N. M. C. et al. Superação da dormência em sementes de atemóia e fruta-do-conde.

Revista. Brasileira de Fruticultura, v.25, n.2, p.305-308, 2003.

TORRES, S. B. Qualidade de sementes de melancia armazenadas em diferentes embalagens e ambientes. Revista Ciência Agronômica, v.36, n.2, p.163-168, 2005. 